\title{
THE QUALITY OF MANAGED CARE: EVIDENCE FROM THE MEDICAL LITERATURE
}

\author{
JOSEPH GOTTFRIED* AND FRANK A. SLOAN**
}

\section{INTRODUCTION}

The past decade has seen a proliferation of state laws aimed at modifying the function of managed care organizations ("MCOs"). ${ }^{1}$ Reaction to the increasing prevalence and novel practices of MCOs has prompted passage of hundreds of state statutes governing everything from direct access to medical specialists, to minimum coverage standards for maternity stays. ${ }^{2}$ The federal government has also taken action on such matters, and the competing "patients' bills of rights" under consideration in Congress would all expand federal oversight of managed care activities. ${ }^{3}$ Though the true impetus for these legal initiatives is debatable, the proponents of "patient protection" measures often cite concern over the quality-or safety-of managed care as the driving force behind their legislative efforts. ${ }^{4}$ Critics contend that MCOs sacrifice high-quality health care for cost savings and provide inferior medical coverage compared

Copyright (C) 2002 by Joseph Gottfried and Frank A. Sloan

This article is also available at http://www.law.duke.edu/journals/65LCPGottfried.

* Resident Physician, Department of Medicine, Duke University Medical Center.

** J. Alexander McMahon Professor of Health Policy, Law and Management, Professor of Economics, and Director of the Center for Health Policy, Law, and Management, Duke University.

This research was supported in part by a grant from the Robert Wood Johnson Foundation awarded to Wake Forest University and administered by the Academy of Health Services Research and Health Policy. Duke University is a subgrantee thereof.

1. For the purposes of this paper, and unless otherwise indicated, "MCOs" (or "managed care organizations") can refer to health maintenance organizations ("HMOs"), independent practice associations ("IPAs"), or preferred-provider organizations ("PPOs"). HMOs can include staff, group, or network models.

2. See, e.g., Russell Korobkin, The Efficiency of Managed Care "Patient Protection" Laws: Incomplete Contracts, Bounded Rationality, and Market Failure, 85 CORNELL L. REV. 1, 15-19 (1999) (tracing the legislative "backlash" against managed care practices); Frank A. Sloan \& Mark Hall, Market Failures and the Evolution of State Regulation of Managed Care, 65 LAW \& CONTEMP. PROBS. 169, 184 (Autumn 2002) (documenting the number and kind of state statutes aimed at managed care).

3. See, e.g., Jill A. MARSTEller \& RANDAll R. BoVBJERG, URBAN INST., FEDERALisM, AND Patient Protection: Changing Roles for State and Federal Government (1999), available at $\mathrm{http}: / /$ newfederalism.urban.org/pdf/occa28.pdf (detailing federal actions affecting managed care and the provisions of federal patient protection proposals).

4. See, e.g., David A. Hyman, Regulating Managed Care: What's Wrong with a Patient Bill of Rights, 73 S. CAL. L. REV. 221, 237-44 (2000) (providing numerous examples of public references by legislators to the supposedly dangerous practices of managed care companies). 
to fee-for-service ("FFS") plans. ${ }^{5}$ Horror stories about alleged abuse or neglect of patients by MCOs have gained wide circulation. ${ }^{6}$ There are even web sites devoted to the promulgation of such anecdotal evidence. ' Opponents of managed care have employed these singular tales of terror to advance their legislative agendas. ${ }^{8}$

This article examines the empirical evidence, drawn from the medical literature, pertaining to the safety of managed care practices. It seeks to ground the ongoing debate on the medical merits of MCOs in the science of clinical research. The article is divided into three major sections. Part II is a systematic review of recent literature on the overall quality of MCOs relative to FFS plans, focusing on clinically important outcome and process measures. It extends previous such analyses to the present day. Part III surveys articles comparing the performance of generalists and specialists in the latter's fields of expertise. It aims to weigh claims about the alleged risks of "gatekeeping," a traditional feature of managed care that has come under increasing criticism. Part IV analyzes the medical evidence on early postpartum discharge ("drive-through deliveries"), perhaps the most publicized example of the supposed dangers of managed care. Though originating in FFS settings, this practice is associated with MCOs due to their widespread adoption of short maternal stays. Finally, the article renders an evidence-based opinion on the quality of America's major form of private health care coverage.

\section{QUALITY-OF-CARE PERFORMANCE: MANAGED CARE VERSUS FEE-FOR-SERVICE}

Considerable data on the quality of care in MCOs versus FFS does exist even though it is conspicuously absent from public debates on the safety of managed care and the need for more patient protection laws in the post-FFS era. Robert Miller and Harold Luft have reviewed much of the early research on this subject, and in 1994 published the first of two literature analyses on the topic.' Examining studies from 1980 through 1993, the investigators found that MCO members were more likely than FFS plan enrollees to receive recom-

5. For the purposes of this paper, and unless otherwise indicated, "FFS" (or "FFS plans") could refer to indemnity insurance, Medicaid, self-pay, Medicare alone, Medicare with supplemental indemnity insurance, or Medicare/Medicaid.

6. See Hyman, supra note 4, at 237-41.

7. Examples include http://consumerwatchdog.org and http://dranonymous.com, which publish alleged examples of HMO wrongdoing. Other sites, such as http://familiesusa.org, solicit stories of managed care abuse from the public.

8. See Hyman, supra note 4, at 237-41.

9. Robert H. Miller \& Harold S. Luft, Managed Care Performance since 1980: A Literature Analysis, 271 JAMA 1512, 1512-14 (1994) [hereinafter Miller \& Luft, Managed Care Performance]. The authors included HMOs and IPAs under managed care, and private indemnity insurance as well as Medicare (but not Medicaid) under fee-for-service. Their paper also considered differences in health care utilization and expenditure between the two systems. 
mended preventive health services. ${ }^{10}$ They also reported that treatment processes and outcomes for a wide range of medical conditions were roughly comparable between the two types of coverage. In 1997, the authors completed a second narrative review on the subject. ${ }^{11}$ Considering studies published since their previous analysis, they concluded that available evidence suggested essentially equivalent quality of care between MCOs and FFS plans. ${ }^{12}$ They cautioned, however, that almost none of the papers in their review included primary data past 1992, when cost cutting by MCOs began in earnest. ${ }^{13}$

In a recent examination of Miller and Luft's methods, Kip Sullivan criticized their analyses for failing to control for differences in the level of coverage between insurance plans. ${ }^{14} \mathrm{He}$ argued that it is misleading to compare "FFS patients who are insured but have inferior coverage (e.g., no coverage for drugs and cancer screens) ... with [MCO] patients who have superior coverage (e.g., coverage for drugs and cancer screens)." ${ }^{15}$ He proposed to exclude from systematic review those articles failing to adjust their results for differences in coverage levels offered by competing plans. ${ }^{16}$ Sullivan correctly called attention to the nature of the "variables" under investigation in individual studies-a point that will be pursued later in this paper with regard to the expansive meaning of "fee-for-service." His ultimate proposal, however, seems misguided. MCOs may well be superior to indemnity insurance precisely because of financial incentives for preventive health care or access to a cheaper formulary. In health service research, such distinctive features of systems of care are presumed to account for differences in research outcomes, and as such represent the focus of investigation. They are not confounding factors that require statistical adjustment.

For the present paper, we conducted a systematic review of the recent medical literature on the quality-of-care performance of MCOs versus FFS plans. Our main goal was to capture studies based on primary data collected since 1992, which, as Miller and Luft suggested, may be more relevant than earlier evidence for understanding current managed care. We sought articles that

10. See id. at 1516. "In seven observations from six studies, HMO plan enrollees consistently received more preventive tests, procedures, and examinations ... or health promotion activities ... than did indemnity plan enrollees." Id. at 1512-14.

11. Robert H. Miller \& Harold S. Luft, Does Managed Care Lead to Better or Worse Quality of Care?, HeAlth AfF., Sept./Oct. 1997, at 7, 7 [hereinafter Miller \& Luft, Does Managed Care Lead]. This time, the authors had to contend with the emergence of PPOs, which they generally grouped with fee-for-service plans, in accordance with the practice of the majority of their included studies. Id. at 9.

12. Id. at 13 ("There were equal numbers of statistically significant positive and negative results for HMO performance, compared with non-HMO plans.").

13. Id. at $16-17$.

14. Kip Sullivan, Managed Care Plan Performance Since 1980: Another Look at 2 Literature Reviews, 89 AM. J. PUB. HeAlth 1003, 1004 (1999).

15. Id. at 1003 .

16. See id. at 1003-04. For his own re-analysis, Sullivan writes that a "study was excluded if it (1) reported that the MCP and FFS groups had different levels of coverage, (2) used utilization rates or some other measure of quality that has been shown to be influenced by differences in insurance coverage, and (3) did not adjust the results for differences in coverage." Id. at 1004. 
examined differences in the rates of medical processes (such as provision of proven preventive measures, recommended medications, or indicated procedures) or outcomes (such as mortality or morbidity from disease). ${ }^{17}$ Studies were included only if they: (1) were published in peer-reviewed journals; (2) were not cited in Miller and Luft's 1997 analysis; (3) concerned the American health care system; (4) examined either processes or outcomes (excluding patient satisfaction); and (5) had reasonable comparison groups. ${ }^{18}$ Each of the final thirty-three studies-including twenty-three retrospective and seven prospective cohort studies, in addition to two surveys and one cross-sectional analysis - was evaluated for its quality of evidence based on the guidelines formulated by David Naylor and Gordon Guyatt. ${ }^{19}$

The thirty-three articles are presented in Tables 1-5, grouped by condition or disease (cardiovascular disease, cancer, geriatrics, pregnancy/pediatrics, and miscellaneous). The tables list the types of coverage compared in each study, as well as its data sources and the variables included in the authors' multivariate analysis (if performed). Before considering the studies as a whole, we discuss the major findings from each group of articles separately.

\section{A. Cardiovascular Disease}

It is not surprising that the largest group of studies looked at cardiovascular disease, the most common cause of mortality in America (Table 1). Five of the articles examined elements in the management of acute myocardial infarction ("AMI"). ${ }^{20}$ Steven Soumerai and his colleagues tested the hypothesis that elderly AMI patients in health maintenance organizations ("HMOs") may suffer as a result of delayed approval of the use of ambulances and emergency serv-

17. More specifically, we performed a Medline search for English-language articles from 1997 to 2001, linking the subject headings "exp managed care programs" and "fee-for-service plans" (or "fees, medical") with the following terms: "exp quality of health care" and "comparative study."

18. This approach yielded twenty-six relevant articles. Four additional papers were identified using a citation search on ISI Web of Science, starting with the above studies and Miller and Luft's reviews. See Miller \& Luft, Managed Care Performance, supra note 9; Miller \& Luft, Does Managed Care Lead, supra note 11. Manual searching of the reference lists within pertinent articles produced three more papers.

19. C. David Naylor \& Gordon H. Guyatt, Users' Guides to the Medical Literature: X. How to Use an Article Reporting Variations in the Outcomes of Health Services, 275 JAMA 554, 554-56 (1996). The authors' criteria for the quality of papers on health services include (1) accurate and comprehensive outcome measures; (2) sensible comparison groups, "similar with respect to important determinants of outcome (other than the one of interest)"; and (3) multivariate analysis to adjust for any imbalances in important prognostic factors among the above groups. $I d$. at 555 .

20. Edward Guadagnoli et al., Appropriateness of Coronary Angiography after Myocardial Infarction Among Medicare Beneficiaries: Managed Care versus Fee-for-Service, 343 NEW ENG. J. MED. 1460 (2000); Danny McCormick et al., Differences in Discharge Medication After Acute Myocardial Infarction in Patients with HMO and Fee-for-Service Medical Insurance, 14 J. GEN. INTERNAL MED. 73 (1999); Mark J. Sada et al., Influence of Payor on Use of Invasive Cardiac Procedures and Patient Outcome After Myocardial Infarction in the United States, 31 J. AM. C. CARDIOLOGY 1474 (1998); Mary E. Seddon et al., Quality of Ambulatory Care After Myocardial Infarction Among Medicare Patients by Type of Insurance and Region, 111 AM. J. MED. 24 (2001); Stephen B. Soumerai et al., Timeliness and Quality of Care for Elderly Patients with Acute Myocardial Infarction Under Health Maintenance Organizations vs. Fee-for-Service Insurance, 159 ARCHIVES INTERNAL MED. 2013 (1999). 
ices. $^{21}$ They found that times to treatment, EKG, and thrombolytic therapy were almost identical for Medicare beneficiaries enrolled in HMOs and FFS plans. ${ }^{22}$ HMO patients were more likely to receive aspirin. ${ }^{23}$ Dr. Mark Sada and his colleagues reported that people in non-Medicare MCO and FFS plans had similar post-AMI mortality at short-term follow-up, though FFS patients more often underwent indicated coronary angiography than MCO enrollees. ${ }^{24}$ Edward Guadagnoli and his colleagues also found that FFS bested MCOs in the rate of indicated angiography after AMI in their study of Medicare beneficiaries. ${ }^{25}$ In articles on use of recommended medications after hospitalization for AMI, Dr. Danny McCormick and his colleagues reported equal rates of receipt of aspirin and beta-blockers by non-Medicare patients in FFS and MCOs, ${ }^{26}$ while Mary Seddon and her colleagues published similar findings for a Medicare population. $^{27}$

Two studies compared the use of higher-quality (lower-mortality) hospitals by FFS and MCO patients for coronary artery bypass graft surgery ("CABG"). Jose Escarce and Mark Pauly observed greater use of such facilities by nonMedicare HMO enrollees in California, but not in Florida. ${ }^{28}$ Medicare FFS patients in Florida, however, were more often admitted to better hospitals than Medicare HMO members. ${ }^{29}$ Dr. Lars Erickson and his colleagues found that people with FFS were more likely than HMO enrollees to receive CABG at a lower-mortality hospital in New York State. ${ }^{30}$ This was true for both Medicare and non-Medicare populations. ${ }^{31}$ Dr. Nathan Every and his colleagues studied the treatment of unstable angina, and found that people with managed care

21. Soumerai et al., supra note 20, at 2013. They also hypothesized, however, that "[s]ome organizational processes and incentives in HMOs may raise the quality of care for acute conditions," citing twenty-four-hour telephone triage systems and institution of treatment protocols and clinical pathways as examples. Id.

22. Id. at 2017-18.

23. Id. at 2018.

24. Sada et al., supra note 20, at 1475 . The investigators included preferred-provider organizations under FFS. Id.

25. Guadagnoli et al., supra note 20 , at 1460 . The authors used stricter criteria than Sada and his colleagues for "appropriate" angiography, assigning each patient in their study to an intervention class according to evidence-based guidelines formulated by the American College of Cardiology and American Heart Association. Id. at 1461.

26. McCormick et al., supra note 20, at 73. The investigators restricted their focus to patients with either commercial indemnity insurance or HMO coverage. Id. at 74.

27. Seddon et al., supra note 20 , at 24 . The authors did observe a higher rate of referrals to cardiac rehabilitation in FFS settings than in MCO settings. Id. at 30.

28. Jose J. Escarce \& Mark V. Pauly, Health Maintenance Organizations and Hospital Quality for Coronary Artery Bypass Surgery, 56 MED. CARE RES. \& REV. 340, 340 (1999). The non-Medicare FFS group in California and Florida included both indemnity insurance and PPO. Non-Medicare HMO enrollees were much less likely to use low-quality hospitals in California than their FFS counterparts. Id. at 348 .

29. Id.

30. Lars C. Erickson et al., The Relationship Between Managed Care Insurance and Use of LowerMortality Hospitals for CABG Surgery, 283 JAMA 1976, 1976 (2000). The mean adjusted mortality at the lower-mortality hospitals was $2.1 \%$, compared to $3.2 \%$ at the higher-mortality hospitals. Id. at 1977.

31. Id. at 1979. 
more often received guideline-recommended medications than those with indemnity insurance. ${ }^{32}$ They observed no difference between these two groups in the rates of in-hospital AMI or death. ${ }^{33}$

In sum, MCOs appear to deliver equal or better medical care to cardiac patients relative to FFS, but equal or possibly worse invasive care (angiography or CABG). As to the latter circumstance, Erickson and his colleagues hypothesized that "[f]inancial risk provides a strong incentive for health plans to select low-priced hospitals," even when available data on quality militate against the use of such facilities (for example, for CABG). ${ }^{34}$ Dr. Sada and his colleagues suggested that the "aggressive cost-containment measures ... found in many HMOs," which should have "their most pronounced effect on discretionary procedures," may also influence payment for nondiscretionary interventions (for example, indicated coronary angiography). ${ }^{35}$ Given the attention paid to invasive procedures such as bypass and catheterization, it is worth noting that perhaps the single most important intervention in cardiology is the provision of an aspirin to a patient with a suspected AMI, which is associated with a $23 \%$ relative reduction - and a $2.4 \%$ absolute reduction - in the rate of cardiovascular death at five weeks. ${ }^{36}$ The finding by Soumerai and his colleagues that HMO members were more likely than their FFS counterparts to receive aspirin for $\mathrm{AMI}^{37}$ seems at least as important as Erickson's discovery of these patients' differential use of lower-mortality hospitals for CABG in New York State. ${ }^{38}$

32. Nathan R. Every et al., Influence of Insurance Type on the Use of Procedures, Medications and Hospital Outcome in Patients with Unstable Angina: Results from the GUARANTEE Registry, $32 \mathrm{~J}$. AM. C. CARDiology 387, 387 (1998). The study included both Medicare and non-Medicare populations. Id. at 388

33. Id. at 390 .

34. Erickson et al., supra note 30, at 1976.

35. Sada et al., supra note 20, at 1478.

36. ISIS-2 Collaborative Group, Randomised Trial of Intravenous Streptokinase, Oral Aspirin, Both, or Neither Among 17,187 Cases of Suspected Acute Myocardial Infarction: ISIS-2, LANCET, Aug. 13, 1988, at 349 (also concluding that aspirin use in AMI patients is associated with a fifty percent relative reduction-and a one percent absolute reduction-in the risk of recurrent infarction at five weeks).

37. Soumerai et al., supra note 20, at 2017. The odds ratio for receipt of aspirin by HMO members, compared to FFS patients, was 1.60 (1.07 to 2.41). Id.

38. Erickson et al., supra note 30, at 1977. The theoretical absolute reduction in the rate of death with universal use of lower-mortality hospitals could be as high as $1.1 \%$. Id. 
Page 103: Autumn 2002] QUALITY OF MANAGED CARE 
[Vol. 65: No. 4 
Page 103: Autumn 2002] QUALITY OF MANAGED CARE 


\section{B. Cancer}

Studies of cancer treatment and outcomes comprised the next largest group of articles, in keeping with the disease's public health importance (Table 2). Three papers focused on breast cancer. Arnold Potosky and his colleagues reported significantly higher survival for Medicare HMO than Medicare FFS breast cancer patients in California (though not in Washington State). ${ }^{39}$ HMO enrollees in both California and Washington State with early-stage disease were more likely to receive breast-conserving surgery ("BCS") with adjuvant radiotherapy. ${ }^{40}$ Gerald Riley and his colleagues, in a similar study by some of the same authors, found that members of Medicare HMOs were less often diagnosed with late-stage breast cancer than their FFS counterparts, and were more likely to receive post-BCS radiotherapy. ${ }^{41}$ In a rare study that distinguished between precise types of Medicare coverage (supplemental indemnity, group model HMO, non-group model HMO, and others), Anna Lee-Feldstein and her colleagues observed no significant differences between $\mathrm{HMO}$ and indemnity breast cancer cases in terms of stage at diagnosis, use of BCS with adjuvant radiotherapy, or mortality. ${ }^{42}$ HMOs were in fact superior to FFS when the latter was defined to include Medicare and Medicare/Medicaid in addition to private supplemental insurance (a definition employed by Potosky and his colleagues, among others). ${ }^{43}$

Results of studies on colorectal cancer were mixed. Ray Merrill and his colleagues reported lower all-cause mortality-as well as increased use of recommended radiotherapy-for Medicare HMO colorectal cancer patients com-

39. Arnold L. Potosky et al., Breast Cancer Survival and Treatment in Health Maintenance Organizations and Fee-for-Service Settings, 89 J. NAT'L CANCER INST. 1683 (1997) [hereinafter Potosky et al., Breast Cancer]. Results were adjusted for age, race, education, stage at diagnosis, whether the cancer was a first primary, and co-morbidity. The investigators, using nearly identical methods as in this study, are responsible for three additional articles on cancer reviewed here. See also Ray M. Merrill et al., Survival and Treatment for Colorectal Cancer: Medicare Patients in Two Groups/Staff Health Maintenance Organizations and the Fee-for-Service Setting, 56 MED. CARE RES. \& REV. 177 (1999); Arnold L. Potosky et al., Prostate Cancer Treatment and Ten-Year Survival Among Group/Staff HMO and Fee-for-Service Medicare Patients, 34 HEALTH SERVICES RES. 525 (1999) [hereinafter Potosky et al., Prostate Cancer]; Gerald F. Riley et al., Stage at Diagnosis and Treatment Patterns Among Older Women with Breast Cancer: An HMO and Fee-for-Service Comparison, 281 JAMA 720, 720 (1999).

40. See Potosky et al., Breast Cancer, supra note 39, at 1689. "On the basis of commonly held assumptions that BCS with adjuvant radiotherapy is associated with a better quality of life and randomized trial evidence of its equivalent efficacy to mastectomy, many medical professionals have recommended that BCS plus radiotherapy represents the best quality of care for early stage breast cancer." Id.

41. Riley et al., supra note 39 , at 720 . The study sample included over 40,000 breast cancer patients, eighty-five percent of them in Medicare FFS. Id. at 721.

42. Anna Lee-Feldstein et al., Breast Cancer Outcomes Among Older Women: HMO, Fee-forService, and Delivery System Comparisons, 16 J. GEN. INTERN. MED. 189, 193-95 (2001).

43. See id. at 194. Odds ratio for Stage I diagnosis, group model HMO vs. "expanded-definition" FFS: 1.68 (1.03 to 2.74). Risk ratio for all-cause mortality, group model HMO vs. "expandeddefinition" FFS: 0.65 (0.44 to 0.98). Potosky and his colleagues reported a comparable risk ratio for allcause mortality of 0.70 (0.62 to 0.79 ). Their definition of FFS was expansive to start. See Potosky et al., Breast Cancer, supra note 39, at 1687. 
pared to FFS cases in California and Washington State. ${ }^{44}$ Cancer mortality was similar between the two groups. Richard Roetzheim and his colleagues, however, in a smaller study from Florida drawing on similar sources of data, found that non-Medicare FFS patients had lower all-cause mortality than their MCO counterparts, perhaps due to increased receipt of chemotherapy. ${ }^{45}$ Medicare plans differed inconsistently in their use of chemotherapy and radiation.

Two additional articles concentrated on genitourinary cancer. Considering data from a single institution in Arizona, Dr. Stephanie Chin and Dr. Keith Harrigill reported no significant difference in the time to definitive surgical therapy for 193 FFS and MCO patients with gynecologic malignancies. ${ }^{46}$ Potosky and his colleagues found that Medicare FFS prostate cancer patients had better cause-specific survival than HMO cases, though the two groups had similar rates of all-cause mortality. ${ }^{47}$

Overall, MCOs (specifically HMOs) appear to offer cancer patients equal or better rates of high-quality care and long-term survival than FFS. Yet most of the evidence for this conclusion comes from studies by one group of investigators working with data from two states, California and Washington. Although the researchers used accurate and comprehensive outcome measures, sensible comparison groups, and multivariate analysis (following large numbers of patients for extended periods of time), their articles are subject to criticism on the grounds of limited external validity. In each of their papers, Potosky ${ }^{48}$ and Merrill $^{49}$ (though not Riley ${ }^{50}$ ) restricted their managed care sample to members of two of the oldest and best-established HMOs in the country. ${ }^{51}$ It could be argued that these benchmark organizations on the West Coast are not representative of the relatively immature managed care market characteristic of most of the country. Still, it would be perverse to claim that managed care is worse than FFS in treating cancer patients when the best available evidence supports the opposite conclusion.

44. Merrill et al., supra note 39 , at 177 . This is the third study by this group, which favored use of a large cancer registry and administrative database as its data source.

45. Richard G. Roetzheim et al., Effects of Health Insurance and Race on Colorectal Cancer Treatments and Outcomes, 90 AM. J. PUB. HEALTH 1746 (2000). The average length of follow-up is not reported in the paper, though it was less than three years. The study period for the article (1994 to 1997) was later than the interval investigated by Merrill and his colleagues (1985 to 1994).

46. Stephanie Chin \& Keith M. Harrigill, Delay in Gynecologic Surgical Treatment: A Comparison of Patients in Managed Care and Fee-for-Service Plans, 93 OBSTETRICS \& GYNECOLOGY 922 (1999).

47. Potosky et al., Prostate Cancer, supra note 39, at 525. The average length of follow-up is not reported in the paper, though it was less than ten years and probably similar to the length in this group's other studies (four to five years). Id. at 526.

48. See id. at 526; see also Potosky et al., Breast Cancer, supra note 39, at 1684.

49. See Merrill et al., supra note 39, at 180-81.

50. See Riley et al., supra note 39, at 721-22.

51. Lee-Feldstein and her colleagues, whose article appears to validate Potosky's results, also set their study in Northern California, where one of these HMOs is a major player. See Lee-Feldstein et al., supra note 42, at 190. 
[Vol. 65: No. 4 
Page 103: Autumn 2002] QUALITY OF MANAGED CARE 
[Vol. 65: No. 4 


\section{Geriatrics}

Six important articles ${ }^{52}$ explicitly examined outcomes for the elderly, a group that may be particularly vulnerable to the possible restrictions of managed care (Table 3). ${ }^{53}$ Sheldon Retchin and his colleagues reported no significant difference in the survival rates of elderly stroke patients in Medicare MCO and FFS plans. ${ }^{54}$ William Getchell and his colleagues found better survival for elderly individuals hospitalized for syncope (fainting) who belonged to a group-model HMO. ${ }^{55}$ Andrew Kramer and his colleagues conducted a cohort study of 429 older stroke victims. ${ }^{56}$ They observed better short-term recovery of function among FFS than HMO enrollees, which they attributed to intensive therapy received at rehabilitation hospitals. ${ }^{57}$ People with FFS plans were also more likely than HMO members to reside in the community at one year, despite the fact that both groups of patients demonstrated equal recovery of function by this point in time..$^{58}$

In another prospective study, Bettina Experton and her colleagues found that "frail" elderly Medicare beneficiaries were more likely to be readmitted to the hospital-including for "preventable" reasons-if they belonged to a network model HMO rather than a supplemental indemnity plan. ${ }^{59}$ Jeremy Holtzman and his colleagues followed 211 elderly patients discharged from the hospital after admissions for stroke, congestive heart failure, chronic obstructive

52. Bettina Experton et al., How Does Managed Care Manage the Frail Elderly? The Case of Hospital Readmissions in Fee-for-Service Versus HMO Systems, 16 AM. J. PREVENTIVE MED. 163 (1999); Jeremy Holtzman et al., The Effect of HMO Status on the Outcomes of Home-Care After Hospitalization in a Medicare Population, 46 J. AM. GERIATRICS SOC. 629 (1998); William S. Getchell et al., A Comparison of Medicare Fee-for-Service and a Group-Model HMO in the Inpatient Management and Long-Term Survival of Elderly Individuals with Syncope, 6 AM. J. MANAGED CARE 1089 (2000); Andrew M. Kramer et al., Outcome and Utilization Differences for Older Persons with Stroke in HMO and Fee-for-Service Systems, 48 J. AM. GERIATRICS SOC. 726 (2000); Frank W. Porell \& Helen B. Miltiades, Disability Outcomes of Older Medicare HMO Enrollees and Fee-for-Service Medicare Beneficiaries, 49 J. AM. GERIATRICS SOC. 615 (2001); Sheldon M. Retchin et al., Outcomes of Stroke Patients in Medicare Fee-for-Service and Managed Care, 278 JAMA 119 (1997).

53. See, e.g., Miller \& Luft, Does Managed Care Lead, supra note 11, at 19. Though these six articles focused on "elder care," the majority of studies in the present review compared various populations of Medicare beneficiaries.

54. See Retchin et al., supra note 52, at 119. The authors did report that MCO enrollees were more likely to be discharged to nursing homes and less likely to be sent to rehabilitation hospitals or units. The clinical significance of this finding is unclear. Id.

55. Getchell et al., supra note 52, at 1089.

56. Kramer et al., supra note 52, at 726.

57. Id. at 732. FFS patients were more often discharged to such specialized facilities. $I d$. at 730 .

58. See id. at 730-31.

59. See Experton et al., supra note 52, at 163. The "frail" elderly were defined as patients who received home health care services prescribed by a physician. Id. at 164 . "Preventable" readmissions were identified using both an algorithm (that defined adverse utilization patterns) and a blinded clinical review. Id. at 166 . The confidence intervals in the study were wide. Id. at 169 . Odds ratio of any readmission: 3.55 with a confidence interval of 1.08 to 11.78 . The odds ratio for preventable readmissions was significant only with use of the algorithm: 5.82 with a confidence interval of 1.36 to 24.87. Id. at 169 . 
pulmonary disease ("COPD"), or hip fracture. ${ }^{60}$ People with Medicare managed care and FFS did not differ significantly in their physical functioning or rates of hospital readmission over the course of one year. ${ }^{61}$ Finally, Frank Porell and Helen Miltiades reported lower mortality rates among moderately disabled Medicare beneficiaries with supplemental insurance than among their counterparts with capitated care. ${ }^{2}$ Their study, which drew from survey data, found no difference in the annual odds of disablement among the two groups of patients. ${ }^{63}$

In general, "frail" or disabled elderly appear to do marginally better in FFS than MCO settings. Investigators have proposed various explanations for this observation. Kramer and his colleagues discussed the financial incentive for MCOs to discharge disabled patients to subacute facilities rather than costlier rehabilitation hospitals, as well as the significant cost savings associated with long-term nursing home placement of frail elders (which may still be less socially desirable than continued community residence) ${ }^{64}$ Experton and her colleagues alluded to "[c]ontractual financial incentives and disincentives" in HMOs that may lead to inappropriately short hospital stays for seniors as well as the withholding of necessary home health care. ${ }^{65}$ Retchin and his colleagues suggested that "subtle declines" in physical or mental function as a result of "fewer [MCO] services in acute care and post-acute care settings" may eventually take their toll on the elderly. ${ }^{66}$ Whatever the reason, the differences in outcomes for seniors - though slight—-seem real.

60. See Holtzman et al., supra note 52, at 629.

61. See id. at 631-32. Physical functioning was measured using a weighted scale of activities of daily living.

62. See Porell \& Miltiades, supra note 52, at 615.

63. Id. at 624-28. The study did find that FFS beneficiaries without supplemental insurance were (1) more likely than those with such coverage to die within a year; and (2) more likely than those with either supplemental coverage or capitated care to become disabled or functionally limited. Id.

64. Kramer et al., supra note 52, at 731-34. "Because HMOs do not cover the cost of long-term nursing home care and receive a higher capitated payment for Medicare services provided to nursing home residents, they have a financial incentive to place costly individuals in nursing homes." Id. at 733 .

65. Experton et al., supra note 52, at 170.

66. Retchin et al., supra note 52, at 122-24. 
Page 103: Autumn 2002] QUALITY OF MANAGED CARE 
[Vol. 65: No. 4 


\section{Pregnancy and Pediatric Disease}

Six articles examined processes and outcomes for pregnancy and pediatric disease (Table 4). Michael Klinkman and his colleagues reported that MCOs and FFS were equally good at providing high-quality prenatal care to expectant mothers. ${ }^{67}$ Denise Oleske and her colleagues studied over 500,000 singleton deliveries in California and Florida and found no significant differences between MCO and Medicaid FFS plans in the rates of serious maternal adverse events. ${ }^{68}$ Oleske co-authored another paper that examined adverse pregnancy outcomes (both maternal and neonatal) in California. ${ }^{69}$ Women in Medicaid MCOs had a lower likelihood of delivering a low-birthweight baby than mothers with Medicaid FFS. ${ }^{70}$

Two single-institution studies focused on children with appendicitis. Stuart O'Toole and his colleagues reported that pediatric patients with MCO and FFS coverage had similar durations of symptoms, times until surgery, and rates of appendiceal perforation. ${ }^{71}$ Vincent Adolph and Kenneth Falterman found a lower rate of late appendicitis in children in MCOs compared to those with indemnity insurance. ${ }^{72}$ In a cross-sectional study of routine pediatric screening from New York City, Karla Hanson and her colleagues discovered that children enrolled in Medicaid capitated care plans were more up-to-date on their immunizations and anemia testing than their counterparts in Medicaid FFS. ${ }^{73}$

At least in this small number of studies, managed care has not been shown to endanger the lives of pregnant women or their children. The issue of early discharge after delivery-a topic that does not clearly oppose MCOs and feefor-service-will be addressed below.

67. Michael S. Klinkman et al., The Effects of Insurance Coverage on the Quality of Prenatal Care, 6 ARCHIVES FAM. MED. 557 (1997). The investigators developed their own set of evidence-based, prenatal care guidelines for the purposes of the study using input from faculty physicians at their institution.

68. Denise M. Oleske et al., Effect of Medicaid Managed Care on Pregnancy Complications, 95 OBSTETRICS \& GYNECOLOGY 6 (2000) [hereinafter Oleske et al., Effect of Medicaid]. The authors considered rates of maternal death, cardiac arrest, excessive blood loss, anesthesia complications, lacerations to the perineum, and eclampsia.

69. Denise M. Oleske et al., A Comparison of Capitated and Fee-for-Service Medicaid Reimbursement Methods on Pregnancy Outcomes, 33 HeAlth SERVICES Res. 55 (1998) [hereinafter Oleske et al., A Comparison]. Like Oleske's later effort, the study employed an administrative database and considered only MCOs that capitated care. See Oleske et al., Effect of Medicaid, supra note 68 .

70. Oleske et al., A Comparison, supra note 69, at 60.

71. Stuart J. O'Toole et al., Insurance-Related Differences in the Presentation of Pediatric Appendicits, 31 J. Pediatric SURgery 1032 (1996). The study considered 202 histologically confirmed cases of acute appendicitis.

72. Vincent R. Adolph \& Kenneth W. Falterman, Appendicitis in Children in the Managed Care Era, 31 J. PEDIATRIC SURGERY 1035 (1996). The MCO group had a statistically nonsignificant lower rate of complications as well.

73. Karla L. Hanson et al., The Transition from a Medicaid Fee-for-Service to Managed Care Among Private Practitioners in New York City: Effect on Immunization and Screening Rates, 2 MATERNAL \& CHILd HEALTH J. 5 (1998). 
[Vol. 65: No. 4 
Page 103: Autumn 2002] QUALITY OF MANAGED CARE 


\section{E. Miscellaneous}

The final studies in this review compared managed care and FFS on a miscellany of process and outcome measures (Table 5). Michael Ward and his colleagues prospectively followed 182 patients with rheumatoid arthritis over ten years: 125 with indemnity insurance and 57 in MCOs. ${ }^{74}$ They reported that "[a]verage global arthritis status scores, pain scores, and functional disability scores were closely comparable in the two groups." 75 Robin Weinick and Karen Beauregard concluded from surveys of nonelderly, privately insured women that MCOs were superior to indemnity plans in the provision of female preventive screening services in 1987, but not in 1992 (when they were equivalent). ${ }^{76}$ Drawing on interview data from the Medical Outcomes Study, Paul Lee and his colleagues found that diabetic patients in MCOs and FFS were equally likely to have used ophthalmic services in the preceding six months. ${ }^{77}$

In a unique prospective study on substance abuse, Arthur Alterman and his colleagues observed that alcohol- and cocaine-dependent people with Medicaid FFS and HMO coverage had similar addiction severity scores more than six months after inpatient treatment. ${ }^{78}$ In another intriguing study, Kelly Kyes and her colleagues followed injured workers from Washington State enrolled in indemnity and pilot managed care plans. ${ }^{79}$ The two groups of patients were similar at six weeks and six months on a number of outcome measures, including freedom from bodily pain and upper-body mobility. ${ }^{80}$ Wilson and his colleagues reported that the physical functioning of AIDS patients in fee-for-service and HMO settings was comparable at four months of follow-up. ${ }^{81}$

74. Michael M. Ward et al., Long-term Health Outcomes of Patients with Rheumatoid Arthritis Treated in Managed Care and Fee-for-Service Settings, 25 J. RHEUMATOLOGY 641 (1998).

75. Id. at 641.

76. Robin M. Weinick \& Karen M. Beauregard, Women's Use of Preventive Screening Services: A Comparison of HMO versus Fee-for-Service Enrollees, 54 MED. CARE RES. REV. 176 (1997). Process measures included Pap smears and breast exams provided to patients in the past year, and all mammograms ever provided to patients.

77. Paul P. Lee et al., A Comparison of Self-Reported Utilization of Ophthalmic Care for Diabetes in Managed Care versus Fee-for-Service, 18 RETINA 356 (1998).

78. Arthur I. Alterman et al., Comparison of Outcomes by Gender and for Fee-for-Service versus Managed Care: A Study of Nine Community Programs, 19 J. Substance AbuSE Treatment 127 (2000). The addiction severity index used in the study was a composite of severity scores from seven different "problem areas," including medical, legal, and psychiatric domains. Id. at 128-29. The HMO capitated care. Id. at 133 .

79. Kelly B. Kyes et al., Evaluation of the Washington State Workers' Compensation Managed Care Pilot Project I: Medical Outcomes and Patient Satisfaction, 37 MED. CARE 972 (1999). The Washington State Department of Labor and Industries selected two managed care organizations (an HMO and PPO) to provide care for occupational injuries and diseases.

80. See id. at 979 . The managed care patients were, however, significantly less satisfied with their overall treatment at six weeks, though not at six months.

81. Ira B. Wilson et al., Costs and Outcomes of AIDS Care: Comparing a Health Maintenance Organization with Fee-for-Service Systems in the Boston Health Study, 17 J. ACQUIRED IMMUNE DEFICIENCY SYNDROME 424 (1998). This was another prospective study using interviews as well as chart reviews. 
Page 103: Autumn 2002] QUALITY OF MANAGED CARE 
[Vol. 65: No. 4 


\section{F. Summary}

What Miller and Luft previously concluded about the quality of MCOs care, compared to that of FFS, ${ }^{82}$ continues to be true: The best available evidence does not demonstrate the clear superiority of one system over the other. If MCOs appear better at medically managing unstable angina, ${ }^{83}$ FFS seems superior at assuring the appropriate use of coronary angiography. ${ }^{84}$ Should the worse outcomes for elderly stroke victims in MCOs be of concern, ${ }^{85}$ so should the shorter survival time of breast cancer patients with FFS. ${ }^{86}$

There are two important caveats to this general assertion of equivalence, both of which undermine the position of managed care. First, the MCO population in many important studies tended to be younger and better educated than the FFS cohort. ${ }^{87}$ The studies' investigators all employed risk-adjustment methods to control for these significant baseline differences between comparison groups. They could not adjust, however, for important prognostic factors of which they were ignorant, or which were not measured and recorded (accurately or inaccurately) in their data sources. ${ }^{88}$ One could speculate that the actions of these silent confounders would bias the studies in favor of MCOs, with their more youthful, educated, and probably healthier populations. Unfortunately, there were no randomized studies in this review to distribute the unknown factors in an unbiased manner. ${ }^{89}$

The second caveat pertains to the types of coverage compared in the articles. Tables 1-5 reveal the multiple permutations of payment methods opposed in the studies. Perhaps most worrisome for the purposes of this review-which really seeks to compare the performance of indemnity-type insurance plans with that of MCOs-is the possible inclusion of Medicaid and self-pay patients

82. See Miller \& Luft, Managed Care Performance, supra note 9, at 1516; see also Miller \& Luft, Does Managed Care Lead, supra note 11, at 13.

83. See Every et al., supra note 32, at 387.

84. See Guadagnoli et al., supra note 20, at 1460.

85. See Kramer et al., supra note 52, at 726.

86. See Potosky et al., Breast Cancer, supra note 39, at 1683.

87. For example, the mean age of MCO patients in every study was sixty-one, compared to sixtyseven for FFS subjects. Every et al., supra note 32, at 389. Only thirty-three percent of the HMO breast cancer patients in the Potosky study were older than seventy-five, compared to forty-six percent of the fee-for-service patients. Potosky et al., Breast Cancer, supra note 39, at 1685. In the Merrill study, thirty-six percent of HMO members in Washington State were in the highest quartile of education level, compared to twenty-four percent of the FFS population. Merrill et al., supra note 39, at 183. MCO stroke patients in both the Retchin and Kramer studies were more often married, with an "able and willing caregiver." See Retchin et al., supra note 52, at 121; see also Kramer et al., supra note 52 , at 730 .

88. See Naylor \& Guyatt, supra note 19, at 556 (discussing risk adjustment methods and the benefits of randomization).

89. Indeed, only seven of the cohort studies in this series were even conducted in a prospective fashion. 
in the FFS category as defined in numerous papers. ${ }^{90}$ Studies-including ones in this review-have shown inferior outcomes for people with Medicaid or no coverage compared with privately insured persons. ${ }^{91}$ Managed care may look even better when compared to FFS if the latter includes patients with public or no insurance. It should be stated, however, that MCOs did outperform indemnity plans outright in several studies. ${ }^{92}$

A final point about the articles in this review concerns their sources of information. As Tables 1-5 indicate, at least one-third of the papers relied heavily on administrative databases: sets of coded diagnoses, procedures, and patient demographics abstracted by technicians from medical records for reimbursement and planning purposes. In their article on health services research, Naylor and Guyatt cited a number of studies that examined the sensitivity and specificity of such sources. ${ }^{93}$ All raised serious doubts about the completeness and accuracy of these databases, which researchers often favor because of their large sample sizes, longitudinal records, and ease of use. ${ }^{94}$ Collectively, they call into question the ability of many studies in this review to control for even obvious and proven prognostic factors, such as the baseline difference in systolic blood pressure between groups of AMI patients with its known effect on mor-

90. Twenty of the thirty-one articles failed to mention "private" or "indemnity" insurance (primary or supplemental) among their Medicare or non-Medicare FFS populations. Some papers explicitly reported Medicaid or self-pay patients among their FFS sample.

91. For example, Medicaid patients in the Sada study were less likely to undergo nondiscretionary angiography, and more likely to suffer adverse events after AMI, than enrollees in indemnity or HMO plans; uninsured individuals also had lower rates of indicated invasive procedures. Sada et al., supra note 20, at 1476-78. In the Lee-Feldstein study, breast cancer cases with Medicare/Medicaid were less often diagnosed with Stage 1 disease and had higher all-cause mortality than patients with private insurance (either FFS or MCO). Women with Medicare alone also had significantly higher all-cause and breast cancer mortality. Lee-Feldstein et al., supra note 42, at 193-95. Children with Medicaid and acute appendicitis in the O'Toole study had significantly higher rates of appendiceal perforation than patients with indemnity insurance or HMO coverage (44\%, 23\%, 27\%). O'Toole et al., supra note 71 , at 1033 .

92. See, e.g., Adolph \& Falterman, supra note 72, at 1035; Escarce \& Pauly, supra note 28, at 340; Every et al., supra note 32, at 387.

93. See, e.g., James G. Jollis et al., Discordance of Databases Designed for Claims Payment versus Clinical Information Systems: Implications for Outcomes Research, 119 ANNALS INTERNAL MED. 844 (1993). The authors compared insurance claims information with prospectively collected data from a cardiac disease registry for almost 13,000 consecutive patients undergoing coronary angiography. Id. at 847. They found that the claims data identified only thirty-nine percent of clinically important conditions recorded in the registry, including hypertension, congestive heart failure, and tobacco use. See also Edward L. Hannan et al., Clinical versus Administrative Data Bases for CABG Surgery, 30 MED. CARE 892 (1992) (comparing a cardiac surgery registry and administrative data set in New York state); David J. Malenka et al., Using Administrative Data to Describe Casemix: A Comparison with the Medical Record, 47 J. CliniCAL EPIDEMIOLOGY 1027 (1994) (finding that claims-based data often underestimated the comorbidity of prostate cancer patients as determined by detailed chart reviews, which were better at controlling for casemix). The chance-adjusted rate of agreement between the two systems, for variables such as hypertension, congestive heart failure, and diabetes, ranged from 0.01 to 0.17 to 0.38 . Id. at 896 . The only kappa values above 0.50 in the study were for in-hospital death, female sex, black race, and PTCA crash. Id. at 896. A logistic regression model derived from the registry contents was significantly better at predicting hospital mortality rates than one founded on claims information. Id. at 898-901.

94. See Jollis et al., supra note 93 , at 844 . 
tality rates. ${ }^{95}$ Insensitive, inaccurate information in a paper does not "help" either MCOs or FFS. Instead, it casts a study's entire findings under a general cloud of suspicion. Though the most recent evidence suggests that MCOs and FFS care for Americans equally well, the randomized trials to prove it-with strictly defined comparison groups and prospectively collected primary dataremain undone.

III

\section{QUALITY-OF-CARE PERFORMANCE: GENERALISTS VERSUS SPECIALISTS}

If there is one feature of managed care that is most often cited as an example of the dangerous, bottom-line mentality of MCOs, it is gatekeeping: the requirement that enrollees obtain specialist referrals from "PCPs" (primary care physicians). While MCOs maintain that this policy limits the inappropriate use of resources, critics assert that any potential restriction of access to experts poses a threat to patients' health. ${ }^{96}$ Let us assume, for the sake of argument, that MCO members with "specialist" diagnoses do in fact see fewer consultants than their FFS counterparts. It is still questionable whether the critics are medically justified in their opposition to gatekeeping, that is, whether the doctors who serve as most PCPs-family physicians ("FPs"), internists, and general practitioners ("GPs")—-do indeed provide worse "expert" care than specialists themselves. To try to resolve this issue, we performed a systematic review of articles on the quality-of-care performance of generalists versus specialists. We conducted separate searches for three common medical consultants: cardiologists, endocrinologists, and gynecologists. ${ }^{97}$

\section{A. Cardiologists}

The largest group of studies focused on cardiologists and management of coronary artery disease ("CAD") and congestive heart failure ("CHF"). A systematic review of much of this literature, by Alan Go and his colleagues, was performed in $2000 .^{98}$ The authors examined twenty-four articles published between 1980 and 1997. ${ }^{99}$ Overall, this research demonstrated that cardiologists adhered to evidence-based guidelines more often than generalists. In particular, specialists were more likely to prescribe recommended medications in the

95. See Kerry L. Lee et al., Predictors of 30-Day Mortality in the Era of Reperfusion for Acute Myocardial Infarction, 91 CIRCULATION 1659 (1995) (identifying significant predictors of death for AMI patients, including preexisting conditions such as hypertension and diabetes).

96. See, e.g., MARSTELlER \& BOVBJERG, supra note 3, at 5 (discussing aspects of utilization management by MCOs).

97. All studies appeared in peer-reviewed journals, focused on physicians in the United States, and employed either processes or outcomes as endpoints.

98. Alan S. Go et al., A Systematic Review of the Effects of Physician Specialty on the Treatment of Coronary Disease and Heart Failure in the United States, 108 AM. J. MED. 216 (2000).

99. See id. at 217. Eight of the twenty-four were physician surveys about knowledge of cardiac disease and (self-reported) practice. More interestingly, from a quality-of-care perspective, fourteen studies described actual practice patterns and six studies reported clinical outcomes. Id. 
setting of an acute myocardial infarction ("AMI") or a CHF exacerbation. ${ }^{100}$ Several studies also revealed that patients treated by cardiologists-for either AMI or CHF - had lower rates of mortality and hospital readmission than those followed by generalists. ${ }^{101}$ Go and his colleagues noted, however, that these differences in short- and long-term outcomes between specialties were slight. ${ }^{102}$

Papers published since Go's review have generally affirmed its conclusions. Three large studies found that cardiologists employed guideline-supported therapies for AMI more frequently than generalists. ${ }^{103}$ One of these articles also reported slightly better survival rates for AMI patients managed by specialists, ${ }^{104}$ as did another study that attributed this result to the higher caseloads of cardiologists. ${ }^{105}$ Andrew Auerbach and his colleagues observed improved survival rates among heart failure patients treated by specialists, ${ }^{106}$ though two other articles found no difference in mortality (or readmission) rates between the CHF cases of cardiologists and generalists. ${ }^{107}$ Randall Stafford and David Blumenthal concluded from survey data that heart doctors provided cardiovascular disease prevention services (especially cholesterol counseling and prescription of lipidlowering agents) more often than internists or FPs. ${ }^{108}$

The studies cited by Go and his colleagues and the more recently published research suffer from many of the same methodological weaknesses discussed in the previous section. All but one were observational in nature, and all but two were retrospectively designed. ${ }^{109}$ Investigators made liberal use of large, administrative databases. Though multivariate analyses abound in these articles, so do potential biases, inaccuracies, and confounding factors. Discussing just one limitation, Go and his colleagues wrote that "[d]ifferent types of patients see

100. Id. at 221 ("There were small differences in the use of medical therapies for myocardial infarction that favored cardiologists.").

101. Id.

102. Id.

103. See Jersey Chen et al., Care and Outcomes of Elderly Patients with Acute Myocardial Infarction by Physician Specialty: The Effects of Comorbidity and Functional Limitations, 108 AM. J. MED. 460 (2000); Sumit R. Majumdar et al., Influence of Physician Specialty on Adoption and Relinquishment of Calcium Channel Blockers and Other Treatments for Myocardial Infarction, 16 J. GEN. INTERNAL MED. 351 (2001); Donald J. Willison et al., Consultation Between Cardiologists and Generalists in the Management of Acute Myocardial Infarction: Implications for Quality of Care, 158 ARCHIVES INTERNAL MED. 1778 (1998).

104. Chen et al., supra note 103 , at 460.

105. See Ira S. Nash et al., Generalist versus Specialist Care for Acute Myocardial Infarction, 83 AM. J. CARDiOLOGY 650 (1999).

106. Andrew D. Auerbach et al., Resource Use and Survival of Patients Hospitalized with Congestive Heart Failure: Differences in Care by Specialty of the Attending Physician, 132 ANNALS INTERNAL MED. 191 (2000).

107. See Kishore J. Harjai et al., Effects of Caregiver Specialty on Cost and Clinical Outcomes Following Hospitalization for Heart Failure, 82 AM. J. CARDIOLOGY 82 (1998); Edward F. Philbin \& Paul L. Jenkins, Differences Between Patients with Heart Failure Treated by Cardiologists, Internists, Family Physicians, and Other Physicians: Analysis of a Large, Statewide Database, 139 AM. HEART J. 491 (2000).

108. Randall S. Stafford \& David Blumenthal, Specialty Differences in Cardiovascular Disease Prevention Practices, 32 J. AM. C. CARDIOLOGY 1238 (1998).

109. As mentioned earlier, such cohort studies are susceptible to a wide range of problems, such as confounding and selection bias, which randomization (in particular) tends to minimize. 
different types of physicians - a form of selection bias that often favors the outcomes of cardiologist-treated patients, who tend to be younger and have fewer comorbid conditions." 110 At the same time, they noted that "there have not been any studies that reported patients treated by generalists had more appropriate treatment or better outcomes than patients treated by cardiologists."111 In general, heart specialists do appear to care for the heart better than other doctors.

\section{B. Endocrinologists}

Comparisons between generalists and specialists other than cardiologists are relatively scarce. This was somewhat surprising in the case of endocrinologists, given the enormous public health burden of diabetes. The Medical Outcomes Study found no significant differences in mean glycosylated hemoglobin ("HgA1C") levels, blood pressure control, or annual mortality rates between the patients of internists, FPs, and endocrinologists. ${ }^{112}$ Marshall Chin and his colleagues reported similar equivalency between physician types-with respect to $\mathrm{HgA} 1 \mathrm{C}$, lipid testing, and retinal exams-for a diabetic population at an academic medical center. ${ }^{113}$ In another article, however, Chin and his colleagues observed that patients of endocrinologists had higher utilization of ophthalmologic screening, lipid testing, and glycosylated hemoglobin measurement than those of generalists. ${ }^{114}$ Jennifer Zgibor and her colleagues replicated these results for $\mathrm{HgA} 1 \mathrm{C}$ and reported lower marker levels among subjects seen by specialists. ${ }^{115}$ Jennifer Lafata and her colleagues discovered that diabetics whose care was shared by generalists and endocrinologists were more likely to receive disease-related preventive health services than the patients of either type of doctor alone. ${ }^{116}$ The last two studies-with hundreds and thousands of patients assigned to the specialist category-were the only ones with enough observations to detect clinically significant differences between comparison groups.

110. Go et al., supra note 98 , at 225 .

111. Id.

112. See Sheldon Greenfield et al., Outcomes of Patients with Hypertension and Non-InsulinDependent Diabetes Mellitus Treated by Different Systems and Specialties: Results from the Medical Outcomes Study, 274 JAMA 1436 (1995). The Medical Outcomes Study followed chronically ill patients-with hypertension, diabetes, AMI, CHF, or depression-over a four-year period in three different cities. Participants belonged to well-established HMOs or FFS plans. See, e.g., Alvin R. Tarlov et al., The Medical Outcomes Study: An Application of Methods for Monitoring the Results of Medical Care, 262 JAMA 925, 926-28 (1989) (describing in detail the design of the Medical Outcomes Study).

113. Marshall H. Chin et al., Variations in the Care of Elderly Persons with Diabetes Among Endocrinologists, General Internists, and Geriatricians, 55 J. GERONTOLOGY 601 (2000).

114. Marshall H. Chin et al., Specialty Differences in the Care of Older Patients with Diabetes, 38 MED. CARE 131 (2000).

115. Janice C. Zgibor et al., The Association of Diabetes Specialist Care with Health Care Practices and Glycemic Control in Patients with Type I Diabetes, 23 DiABETES CARE 472 (2000).

116. Jennifer E. Lafata et al., Provider Type and the Receipt of General and Diabetes-Related Preventive Health Services Among Patients with Diabetes, 39 MED. CARE 491 (2001). 


\section{Gynecologists}

The performance of gynecologists ("GYNs") relative to PCPs has also received scant attention from clinical researchers. Peter Curtis and his colleagues reported that GYNs, as a group, submitted a higher proportion of satisfactory Pap smears to a commercial laboratory than generalists. ${ }^{117}$ Corroborating these results, Kevin Fiscella and Peter Franks found that Pap smears performed by FPs more often lacked an endocervical component than ones done by gynecologists. ${ }^{118}$ Karl Finison and his colleagues used over 186,000 Medicare Part B claims to conclude that women whose "usual care" physician was a gynecologist had higher rates of mammography (seventy-eight percent) than those treated primarily by internists (sixty-seven percent) or other doctors. $^{119}$ In a survey by Kathleen Torkko and her colleagues, generalists and GYNs reported testing sexually active adolescent females equally often for chlamydia. ${ }^{120}$ A survey by Laurel Desnick and her colleagues discovered that FPs were less likely than GYNs to perform screening clinical breast examinations in women aged fifty to seventy-five. ${ }^{121}$ Yet another survey found that generalists and GYNs recommended regular Pap smears and annual mammography with equal frequency, ${ }^{122}$ though it concluded-from interviews with patients as well as physicians-that GYNs more often suggested and succeeded in obtaining Pap smears in women aged forty-five and older. ${ }^{123}$ Along similar lines, a case-control study by David Celentano and his colleagues determined that having seen a GYN at any point in a patient's life protected against cervical cancer (as did a recent visit to an internist). ${ }^{124}$

\section{Summary}

Though the quantity of the above evidence for gynecologists and endocrinologists is small, and its overall quality is poor, what was true for cardiologists still seems true for these specialists: They appear to outperform generalists in their field of expertise. Nevertheless, even for cardiologists, this statement is qualified by the paucity of outcome data and near absence of both prospective

117. Peter Curtis et al., Characteristics and Quality of Papanicolaou Smears Obtained by Primary Care Clinicians Using a Single Commercial Laboratory, 8 ARCHIVES FAM. MED. 407 (1999).

118. Kevin Fiscella \& Peter Franks, The Adequacy of Papanicolaou Smears as Performed by Family Physicians and Obstetrician-Gynecologists, 48 J. FAM. PRAC. 294 (1999).

119. Karl S. Finison et al., Screening Mammography Rates by Specialty of the Usual Care Physician, 2 EFFECTIVE CliniCAL PRAC. 120 (1999).

120. Kathleen C. Torkko et al., Testing for Chlamydia and Sexual History Taking in Adolescent Females: Results from a Statewide Survey of Colorado Primary Care Providers, 106 PediATRICs 32 (2000).

121. Laurel Desnick et al., Clinical Breast Examination in Primary Care: Perceptions and Predictors Among Three Specialties, 8 J. WoMEN's HEALTH 389 (1999).

122. See Carla J. Herman et al., Variation in Recommendations for Breast and Cervical Cancer Screening Among Primary Care Physicians in North Carolina, 1991, 89 S. MED. J. 583 (1996).

123. Martha A. Teitelbaum et al., Specialty Differences in Physicians' Recommendations in Relation to Women's Pap Testing Behavior, 26 MED. CARE 607 (1988).

124. David D. Celentano et al., Cervical Cancer Screening Practices Among Older Women: Results from the Maryland Cervical Cancer Case-Control Study, 41 J. ClinICAL EPIDEMIOLOGy 531 (1988). 
studies and randomized trials in this review, although the result is plausible and supported by some evidence. It is not clear, however, that this conclusion represents an indictment of managed care. The premise for this section has been that gatekeeping prevents MCO members with specialized problems from accessing the experts available to FFS patients. But if, for example, PCPs in MCOs regularly denied people with AMI or CHF the superior services of a cardiologist, it should somehow be reflected in worse outcomes or process measures for these enrollees. Yet MCOs rival FFS in the quality of care for cardiac cases, as demonstrated in the previous section and Table 1. The same holds true for most types of patients. Gatekeeping's potential for harm seems, in fact, limited to theory.

IV

\section{EVIDENCE FOR HARM: EARLY DISCHARGE AFTER DELIVERY}

Early hospital discharge of mothers and newborns after delivery-a phenomenon that antedated the ascendancy of managed care, but one embraced and encouraged by MCOs as a cost-containment strategy-aroused fierce political hostility in the 1990s, prompting passage of federal and state laws curtailing its private enforcement. ${ }^{125}$ Though medical evidence apparently played little role in the legislative debate ${ }^{126}$ outcome studies on the effects of rapid postpartum discharge are in fact available, most of which use maternal or neonatal readmission as a surrogate endpoint for significant medical problems. ${ }^{127}$ It is of interest to review this evidence to determine if there was indeed a scientific basis for the statutory changes that were aimed at managed care.

Two systematic reviews have already been performed on the subject. In 1995, Paula Braveman and her colleagues examined articles on early discharge published between 1975 and $1994 .{ }^{128}$ They found serious methodological flaws with the eighteen studies that examined maternity stays of less than forty-eight hours, including a lack of appropriate comparison groups and "inadequate description of participation criteria, protocols, or loss to follow-up." 129 The three randomized trials in the review were not large enough to detect small but clinically significant differences in maternal and neonatal outcomes. Braveman and her colleagues also called attention to the strict inclusion criteria of many studies, which they believed limited their external validity. ${ }^{130}$ Kenneth Grullon

125. See, e.g., David A. Hyman, Drive-Through Deliveries: Is "Consumer Protection” Just What the Doctor Ordered?, 78 N.C. L. REV. 5 (1999) (detailing the national, historical trend toward early discharge and the success of the anecdote-driven campaign against it).

126. See id. at 20 ("Empirical studies casting light on the issue were ignored, and the debate was driven by a handful of anecdotes.").

127. See id. at 45-46. Hyman argues that readmission is both overinclusive and underinclusive as an endpoint, subject to both detection and selection bias.

128. Paula Braveman et al., Early Discharge of Newborns and Mothers: A Critical Review of the Literature, 96 PEDIATRICS 716 (1995).

129. Id. at 724 . The eighteen studies presumably concerned vaginal delivery only.

130. See id. (noting the "stringent selection criterion" of the studies). 
and David Grimes published another literature analysis two years later, this one capturing articles from 1966 through the beginning of 1997 (including two additional randomized, controlled trials). ${ }^{131}$ They too found fatal flaws with the studies in their review, including self-selection bias, exclusion of patients after randomization, and inadequate sample sizes. "The evidence," they wrote, "that early postpartum discharge is as safe as traditional stay stems from cohort and case-series studies with highly selected patients with extensive antepartum and postpartum education and uncomplicated deliveries." ${ }^{, 132}$ Like Braveman and her colleagues, they were unable to render any evidence-based expert opinion on the safety of routine rapid discharge.

More recently, the results of several well-designed studies on the risks of short postpartum stays have been published. Bruce Edmonson and his colleagues performed a case-control study in Wisconsin on neonatal readmissions for feeding-related problems. ${ }^{133}$ They found that 210 cases were no more likely than 630 controls to have been discharged within two days of delivery. The investigators adjusted their risk estimates for a variety of maternal and newborn factors, including primiparity, birth weight, preterm status, and nursery feeding type. $^{134}$ Another case-control study, by Lenna Liu and her colleagues, challenged these findings. ${ }^{135}$ In this population-based analysis from Washington State, 2029 cases (neonates rehospitalized within one month of birth) were more likely than 8657 controls (newborns not readmitted) to have been discharged within thirty hours of delivery. ${ }^{136}$ Liu and her colleagues adjusted their results for multiple maternal and newborn characteristics as well.

In a commentary accompanying these two articles, Braveman and her colleagues sought to explain why studies with similar methodologies appeared to have reached conflicting results. ${ }^{137}$ They observed that the Wisconsin study had an insufficiently large sample to detect a difference as small as that reported by

131. Kenneth E. Grullon \& David A. Grimes, The Safety of Early Postpartum Discharge: A Review and Critique, 90 OBSTETRICs \& GYNECOLOGY 860 (1997). The authors limited themselves to studies on hospital discharge within forty-eight hours after vaginal delivery, and within ninety-six hours after cesarean delivery. They examined a total of twenty-eight articles.

132. Id. at 864

133. M. Bruce Edmonson et al., Hospital Readmission with Feeding-Related Problems After Early Postpartum Discharge of Normal Newborns, 278 JAMA 299 (1997). Cases comprised newborns readmitted in the first month of life for feeding problems. The authors hypothesized that early discharge may jeopardize inpatient instruction of new mothers on breast-feeding and infant nutrition. They thus chose feeding-related readmissions as their outcome measure. The study cohort consisted of singleton newborns delivered vaginally between 1991 and 1994, "having normal birth weights ... and continuous, uncomplicated stays at their birth hospitals until discharge on day one or two (early discharge) or day three (conventional discharge)." Id. at 299.

134. Id. at 301 .

135. Lenna L. Liu et al., The Safety of Newborn Early Discharge: The Washington State Experience, 278 JAMA 293 (1997).

136. See id. at 296. Odds ratio for rehospitalization at seven days: 1.28 with a confidence interval of 1.11 to 1.47; at fourteen days: 1.16 with a confidence interval of 1.03 to 1.32 ; at twenty-eight days: 1.12 with a confidence interval of 1.00 to 1.25 .

137. Paula Braveman et al., Early Discharge and Evidence-Based Practice: Good Science and Good Judgment, 278 JAMA 334 (1997). 
the Washington State investigators. ${ }^{138}$ They contended that this difference (a higher risk of infant readmission of around $20 \%$ to $30 \%$ ) may not seem enormous, but that "because birth is such a common event, there is considerable public health significance of a $20 \%, 10 \%$, or even a $5 \%$ increased risk of serious adverse events when it affects the entire maternal-newborn population." ${ }^{\prime 139}$ It also seems noteworthy that the two studies employed different outcome measures, and that their comparative results do not necessarily conflict. ${ }^{140}$

Two other studies published subsequent to Braveman and her colleagues' commentary also merit mention. Elizabeth Bragg and her colleagues reported that neonatal readmission rates did not change at their institution after implementation of an early-discharge program for postpartum patients. ${ }^{141}$ Candidates for discharge "were required to be free of medical complications, be physiologically stable, have no history of substance abuse, and be at least 18 years old or have a stable and supportive environment at home." ${ }^{142}$ They received home visits from nurse clinicians, who conducted physical assessments of the mother and child and provided education and lactation support. The investigators did not adjust their results for significant baseline differences between the (noncontemporanous) groups of infants, including birth weight and gestational age. ${ }^{143}$ In addition, their study sample was only powered (at $80 \%$ ) to detect a doubling of the rate of readmission within the $1 \%$ to $2 \%$ range. ${ }^{144}$

Uma Kotagal and her colleagues conducted a much larger retrospective cohort study - also with an historical control—using Medicaid claims data from Ohio linked to vital statistics files. ${ }^{145}$ The authors observed a significant decrease in the rehospitalization rate for neonates as the average length of postpartum stay in the population fell from 2.2 days in 1991 to 1.6 days in

138. See Edmonson et al., supra note 133, at 300; see also Braveman et al., supra note 137, at 335 (stating that their sample size had $82 \%$ power to detect a true odds ratio (OR) of 1.6 or greater (at alpha=.05). Braveman and her colleagues calculated that this sample size had statistical power of only $32 \%$ to detect a true OR of 1.3 or greater (using the OR for rehospitalization at seven days in Liu's study as a reference). See id. at 334.

139. Id. at 335 .

140. For example, in a subgroup analysis, early discharge in the Liu study was not associated with a significantly increased risk of rehospitalization for dehydration, one of the primary outcomes in Edmonson's study. See Liu et al., supra note 135, at 296; see also Edmonson et al., supra note 133, at 300 .

141. Elizabeth J. Bragg et al., The Effect of Early Discharge After Vaginal Delivery on Neonatal Readmission Rates, 89 OBSTETRICS \& GYNECOLOGY 930 (1997). The authors enrolled 6267 vaginally born infants in the study. They calculated separate readmission rates for neonates discharged within one hospital day and within twenty-four hours of delivery, neither of which differed from that of the conventional discharge period group. Readmission was defined as an admission occurring within ten days of birth. $I d$.

142. Id. at 931.

143. See id. at 931-32. The average birth weight of infants in the conventional-discharge group was 3086 grams, compared to 3209 grams for infants in the early-discharge group.

144. See id. at 932.

145. Uma R. Kotagal et al., Safety of Early Discharge for Medicaid Newborns, 282 JAMA 1150 (1999). The study's main outcome measures were rehospitalization within seven and fourteen days of discharge. 
$1995,{ }^{146}$ and as the proportion of "short stays" rose from $21.0 \%$ to $59.8 \%$ of all births. ${ }^{147}$ Their sample of 102,678 infants was powered (at $90 \%$ ) to detect a $13 \%$ difference in the rate of readmission (from $1.3 \%$ to $1.13 \%$ ). ${ }^{148}$ In a multivariate logistic regression model that controlled for maternal and neonatal characteristics (many of which varied significantly over the course of the study period), short stay was not associated with an increased risk of rehospitalization at either seven or fourteen days after discharge. ${ }^{149}$ The investigators, however, noted an annual increase in the proportion of newborns who received a primary care visit within fourteen days of birth. ${ }^{150}$

The above study (like the one by Bragg and her colleagues) suffers from the use of an historical control. The readmission rate for neonates may have fallen even further in Ohio if the average length of postpartum stay had not decreased between 1991 and 1995. Nevertheless, the analysis does provide some reassurance that rapid discharge (with decent follow-up) did not result in the wholesale slaughter of helpless infants, as some opponents of the practice seemed to suggest. ${ }^{151}$ Based on Liu and her colleagues' superior study from Washington State, it is still possible that short stays are associated with a modest increase in the risk of infant readmission, which - though important in itself-does not directly translate into death or disability (or even harm). It may be infeasible to conduct a randomized, controlled trial to provide conclusive evidence of the effects of early discharge on readmissions. ${ }^{152}$ At this point, it would also be illegal, as state and federal legislation mandating minimum forty-eight hour maternity stays has rendered moot the legitimate medical debate over the safety of "drivethrough deliveries."

\section{V}

\section{CONCLUSION}

The empirical evidence from the medical literature does not support the allegations of unsafe practices made against MCOs by proponents of patient protection legislation. This finding holds despite data suggesting that generalists, who occupy a privileged position as gatekeepers in many MCOs, are less proficient than specialists in the latter's areas of expertise, because such a fact does not appear to translate into worse specialty care for patients in managed

146. See id. at 1153-54. Rehospitalization rates within seven days of discharge decreased by $23 \%$, from $1.3 \%$ in 1991 to $1.0 \%$ in 1995 ( $\mathrm{p}=.01)$. Rates within fourteen days of discharge decreased by $19 \%$, from $2.1 \%$ in 1991 to $1.7 \%$ in $1995(\mathrm{p}=.03)$.

147. See id. at 1151. A "short stay" was defined as discharge within one day of vaginal delivery, and two days of cesarean delivery.

148. Id. at 1155 .

149. Id. at $1154-55$.

150. Id. at 1153 .

151. See, e.g., Hyman, supra note 125 , at $81-86$ (citing rash remarks by politicians on the supposed dangers of early discharge).

152. See Braveman et al., supra note 137, at 335. "At an underlying [neonatal] rehospitalization rate of $2 \%$, it would take at least 14,000 patients in each of 2 groups to detect a $25 \%$ increase in rehospitalizations related to discharge timing." $I d$. 
care plans. This paper's conclusion would be weakened if future studies confirmed the association between early postpartum discharge-a practice strongly encouraged in the past by MCOs-and infant readmissions observed by investigators from Washington State. Though only a surrogate marker for harm (and one of unknown long-term significance), rehospitalization of neonates is probably something best avoided, even at considerable cost to the health care system.

Nevertheless, sound reasons for increased regulation of MCOs may in fact exist. Consumer dissatisfaction with managed care has been well documented, ${ }^{153}$ and provisions in the law for such arrangements as direct access to medical specialists may well reflect the simple desire of the voting public. The wishes of the majority-even if arbitrary or harmful by empirical standards-should carry weight in a democratic society. It seems dishonest, however, for critics to claim that the provisions of a patient's bill of rights are necessary to protect the health of MCO enrollees. A substantive body of scientific evidence suggests that managed care is as safe as the system it has replaced, its product as fit for popular consumption as traditional, less affordable indemnity insurance.

153. See, e.g., Robert J. Blendon et al., Understanding the Managed Care Backlash, 17 HEALTH AFF. July/Aug. 1998, at 80 (discussing the results of a nationwide survey on managed care). 